\title{
O Conceito de Formação nas Propostas Curriculares da Psicologia brasileira de 1932 e 1962
}

\author{
The Concept of Formation in the Curriculum Proposals of Brazilian \\ Psychology of 1932 and 1962
}

\author{
Danillo Lisboa \\ Carmen Lúcia Cardoso \\ Universidade de São Paulo \\ Roberta Vasconcelos Leite \\ Yuri Elias Gaspar \\ Universidade Federal dos Vales do Jequitinhonha e Mucuri \\ Brasil
}

\begin{abstract}
Resumo
O presente estudo objetiva compreender a ideia de formação que perpassa as primeiras propostas curriculares para o ensino da Psicologia no Brasil. Para o alcance deste objetivo foi utilizada abordagem descritiva e analítica da história da Psicologia científica, a partir do estudo de duas fontes principais, sendo elas o currículo de 1932 proposto por Waclaw Radecki e o currículo mínimo de 1962 reconhecido pelo Estado brasileiro, além de fontes complementares que versam sobre o tema. Foram identificadas duas categorias que circularam as proposições curriculares do ensino em Psicologia no Brasil, a saber: formação do psicólogo generalista e do especialista, sendo prevalente esta última. Concluímos que as propostas formativas que visaram alcançar o perfil do graduado em Psicologia no Brasil, sobretudo em sua gênese, revelam muito mais uma reação às questões político-sociais e culturais da época do que a construção de um sentido próprio para a formação do psicólogo brasileiro.
\end{abstract}

Palavras-chave: Formação do Psicólogo; Currículo Mínimo; História da Psicologia.

\begin{abstract}
This study aims to understand the idea of education that permeates the first curricular proposals for the teaching of Psychology in Brazil. To achieve this objective, we used the descriptive and analytical approach of the history of scientific Psychology, from the study of two main sources, namely the 1932 curriculum proposed by Waclaw Radecki and the 1962 minimum curriculum recognized by the Brazilian State, in addition to complementary sources that deal with the subject. Two categories were identified that circulated as curricular propositions for teaching Psychology in Brazil, namely: education of the generalist and specialist psychologist, the latter being prevalent. We conclude that the educational proposals that aimed to reach the profile of Psychology graduates in Brazil, especially in their genesis, reveal much more a reaction to the political, social and cultural issues of the time than the construction of a proper meaning for the education of the Brazilian psychologist. Keywords: Psychologist Education; Minimum Curriculum; History of Psychology.
\end{abstract}


A Psicologia brasileira, em 2020, completou 58 anos de regulamentação da profissão no país. A diversidade de contribuições que atravessam esse campo de conhecimento, as especificidades do seu surgimento no Brasil e a impossibilidade de fornecer uma formulação unívoca sobre a própria conceituação do que é Psicologia (Massimi, 2016), traduzem a complexidade da trajetória formativa desse profissional. Cientes disso e, em consonância com a orientação de JacóVilela (2002), este estudo não partirá do "zero" para apontar uma origem específica da Formação em Psicologia no Brasil, mas se valerá de datas específicas, favorecidas e reconhecidas pelo Estado, que possibilitaram a emergência de propostas e cursos específicos para essa formação profissional no país, com o objetivo de compreender a ideia de formação que perpassa as primeiras construções curriculares para o ensino da Psicologia no Brasil.

Assim, faremos um resgate das propostas curriculares dos cursos de Psicologia no Brasil a partir de duas fontes principais: 1) o currículo de 1932 proposto por Waclaw Radecki e 2) o currículo mínimo de 1962 reconhecido pelo Estado brasileiro. Como fontes complementares, serão utilizados: Decreto $\mathrm{n}$. 21.173, 1932; Centofanti (1982); Lei n. 4.119; Parecer n. 403 (1962); Jacó-Vilela (2002); e Bernardes (2006).

Comungamos do entendimento do Conselho Federal de Psicologia (1988, 2018) e de Edith Stein (1930/2003), de que cada projeto de formação, nos diversos campos, carrega consigo visões de mundo e de ser humano que the dão sustentação. Entendemos que explorar o conceito de formação em propostas curriculares brasileiras para a Psicologia pode contribuir para a problematização de aspectos da identidade deste profissional à medida que esclarecermos seus fundamentos. Considerando ainda a importância de reconstruir acontecimentos históricos situando-os em seu contexto de constituição, este trabalho dialoga com abordagem descritiva e analítica da história da Psicologia científica (Massimi, Campos \& Brožek, 1996), dada sua intenção de investigar o conceito de formação a partir da análise de fontes principais e complementares relativas aos currículos de 1932 e 1962.

A partir da leitura de tais fontes identificamos duas categorias que circularam as proposições curriculares do ensino em Psicologia no Brasil, a saber: formação do psicólogo generalista e formação do psicólogo especialista. De modo amplo, a primeira se caracteriza por visar uma formação polivalente e que seja capaz de favorecer a formação de um profissional apto a ofertar uma atenção psicológica em diferentes contextos, embasados em conhecimentos, atitudes e habilidades que resultem em competências para 0 atendimento integral dos 
públicos alvos e situações de intervenção. Essa perspectiva vislumbra ainda abranger diversidade teórica-metodológica e evitar a especialização precoce em áreas específicas da profissão. Já a perspectiva da formação do psicólogo especialista, aponta para um currículo mais tecnicista e linear, atento a uma formação que atenda a determinados objetivos, grades e conteúdos préestabelecidos a partir de pareceres gerais e padronizados, contribuindo para uma identidade profissional mais segmentada e com um arcabouço teórico apto à aplicação em áreas específicas como a educação, clínica e/ou indústria.

Tal embate em torno da formação do profissional da Psicologia no Brasil marcou a construção do currículo mínimo deste "novo" profissional e a partir dessa seara de constituição da formação em Psicologia no Brasil que retomaremos algumas das discussões que levaram à formulação das propostas curriculares em questão, com atenção aos interesses grupais e profissionais em jogo em cada momento histórico.

\section{Primórdios da formação profissional em Psicologia no Brasil}

O processo de formação profissional em Psicologia no Brasil, como conhecemos hoje, envolve uma série de acontecimentos que contribuíram gradativamente para que a ciência psicológica fosse ganhando notoriedade no cenário nacional (Massimi, 1990; Penna, 1992).

Através de um recorte temporal, observamos que a partir da última década do século XIX, as produções relacionadas ao estudo e intervenção sobre os fenômenos psicológicos que já ocorriam em outras partes do mundo, especialmente na Europa, ganharam relevo no Brasil graças a uma pluralidade de atores e instituições. Destacam-se como espaços onde os temas de natureza psicológica eram discutidos: os Laboratórios Experimentais, as Escolas Normais, as Faculdades de Medicina. Isso significa que tais temas aqui aportaram muito antes que a formação e a profissão do psicólogo estivessem reconhecidas pelo Estado brasileiro (Antunes, 1997; Lei no 4119, 1962).

Apropriando-se de produções oriundas do exterior, o campo da Psicologia científica brasileira teve sua aglutinação inicial marcada por um modo próprio de se fazer, notadamente, a múltiplas mãos. De acordo com Pineda e Jacó-Vilela (2014), entre 1910 e 1930, já havia uma "formação" em Psicologia no Brasil e esta era basicamente autodidata - mediante livros importados - e complementada por viagens e convites a agentes do exterior. Nesse mesmo período, os laboratórios experimentais já existentes começaram a conviver com as inovações dos testes psicológicos, também em franco desenvolvimento pelo mundo, o que elevou o 
interesse e a difusão da ciência psicológica pelo país (Antunes, 1997).

Esse conhecimento emergente aguçou o interesse de profissionais de várias áreas, que puderam acessá-lo vinculando-se a instituições, grupos de estudos e práticas profissionais que, de algum modo, versavam sobre o saber psicológico no país. Nesse movimento, médicos, advogados, pedagogos, professores e, posteriormente, até engenheiros e administradores puderam usufruir do conhecimento psicológico e aplicá-lo em seus contextos de atuação (Pineda \& JacóVilela, 2014).

Grande contribuição para o estabelecimento da Psicologia no Brasil e principalmente para a formação de profissionais capacitados para a atuação nessa área veio das Escolas Normais (...). A Psicologia encontrou nas escolas normais um dos mais importantes substratos para seu desenvolvimento, seja pela divulgação das ideias que vinham sendo produzidas nos mais importantes centros europeus e norte-americanos, seja pela aplicação de seus conhecimentos, pela produção de pesquisas e sobretudo, pela formação de profissionais que viriam a ser alguns dos primeiros a se dedicar exclusivamente a esta ciência. É possível mesmo afirmar que as escolas normais foram fundamentais na definição do perfil desses profissionais que se tornariam especialistas em Psicologia: os então denominados "psychologistas" (Antunes, 1997, p. 43).

O saber psicológico difundido e construído nas Escolas Normais - somado à crescente utilização dos testes psicológicos como ferramenta para o movimento da Escola Nova na construção de classes homogêneas - foi rapidamente considerado e absorvido pelas recém-criadas instituições universitárias do Brasil da década de 1930 (Piñeda \& Jacó-Vilela, 2014). Isso favoreceu, ainda que de modo incipiente, que o conhecimento da ciência psicológica adentrasse o ensino superior brasileiro nas diferentes áreas de formação profissional.

Nesse contexto de crescente difusão da Psicologia no país, surge o interesse na capacitação de profissionais que pudessem se comprometer com o desenvolvimento da ciência psicológica como um todo, tornando-se eminente o anseio por padronizar um projeto de formação e desenvolvimento científicoprofissional. Neste período a ciência psicológica já era um fato, mas a formação do seu profissional ainda era difusa e aqueles que desejavam alcançar o conhecimento específico da Psicologia o faziam através do curso específico de disciplinas com conteúdo "psicológico" oferecidas em outros cursos, como a Pedagogia, Filosofia e Medicina, em cursos de especialização e nas disciplinas presentes nas Escolas Normais. 
Os técnicos nos vários campos da educação, os psicometristas, os psicólogos clínicos e higienistas mentais, os técnicos em seleção de pessoal e orientação profissional, que trabalham nos diferentes serviços estatais e paraestatais, são recrutados entre os diplomados por aquelas escolas (normais), que, se não thes dão treino propriamente profissional, dão-lhes boa base para finalmente adquirir essa experiência no emprego. [...] O que é possível por não existir qualquer regulamentação da profissão de psicologista no Brasil (Cabral, 1950, citado por Antunes, 1997, pp. 44-45).

A formação prática e investigativa que permitiu à Psicologia o alcance de uma estatura e desenvolvimento já na década de 1930, indica-nos que a ideia de formação difundida nessa época privilegiava a aplicação da técnica, ou seja, o treino orientado pelas teorias com finalidade de favorecer uma Psicologia especializada e aplicada. Contudo, a cada aplicação da teoria, novas questões surgiam, ampliando a necessidade de regulamentação e de ampliação do debate sobre como seria construída a profissão no país.

\section{O primeiro currículo para a formação de Psicólogos brasileiros e seus desdobramentos}

Em 19 de março de 1932, foi instituída oficialmente, através decreto $\mathrm{n}$. 21.173, a primeira instituição brasileira apta a "formar psicologistas profissionais, mediante cursos teóricos e práticos" (Decreto n. 21.173, 1932, s. p.).

Tendo em vista a crescente presença dos laboratórios de Psicologia no país desde 0 final do século XIX, o autodidatismo que marcava a busca pelo conhecimento psicológico até a década de trinta e a inserção de disciplinas de Psicologia em cursos superiores, em 1932, o decreto 21.173 reconheceu as "importantes aplicações" da técnica psicológica nas organizações, na orientação e seleção de profissionais, na Medicina, no Direito e na Educação. O decreto converteu o então Laboratório de Psicologia da Colônia de Psicopatas, no Engenho de Dentro (Rio de Janeiro), em Instituto de Psicologia, apto a ser um centro coordenador de Psicologia geral e aplicada do Brasil. Entre os objetivos do Instituto, destacam-se:

a) coordenar estudos e pesquisas de Psicologia geral e aplicada; b) servir como centro de aplicação das técnicas de diagnose psicológica, para os serviços de orientação e seleção profissionais; c) contribuir para os estudos de aplicação da Psicologia à Pedagogia, Medicina, técnica judiciária e racionalização do trabalho industrial; d) formar psicologistas profissionais, mediante cursos teóricos e práticos, e com estágio obrigatório em seus laboratórios (Decreto n. 21.173, 
1932, s. p. - grifo nosso).

Esse decreto respondeu aos anseios de proeminente figura do cenário psicológico da época, enfático defensor da necessidade de formar profissionais psicólogos na década de 1930: Waclaw Radecki, psicólogo polonês com sólida formação acadêmica obtida na Europa, assistente de Claparède no Instituto Jean Jacques Rousseau em Genebra. Desde 1923 Radecki residia no Brasil e em 1924 aceitou o convite de Gustavo Riedel para dirigir o Laboratório de Psicologia da Colônia de Psicopatas do Engenho de Dentro (Autuori, 2014; Centofanti, 1982).

Radecki obteve o título de doutor na Universidade de Genebra, onde a Psicologia era desenvolvida entre os cursos de licenciatura em ciências naturais e não entre os de filosofia, condição que favoreceu seu empenho no desenvolvimento do "espírito" experimental da Psicologia no Brasil na época (Mancebo, 1999). O interesse de Radecki pela investigação experimental dos fenômenos psicológicos também atraiu a atenção de profissionais de variadas formações, como médicos, advogados e professores que endossavam a divulgação da Psicologia pelo país (Centofanti, 1982; Jacó-Vilela, 2002).

O cenário efervescente da década de 1930, consolidou a criação do Ministério da Educação e Saúde Pública e, em 1931, um conjunto de sete decretos (conhecidos como Reforma Francisco Campos) determinou a criação do Conselho Nacional de Educação, a adoção do regime universitário e a organização do ensino superior brasileiro, tornando a educação uma questão nacional (Saviani, 2013). Este cenário favoreceu que, através do recém-criado Instituto de Psicologia, Radecki propusesse um currículo para formação do psicólogo. A proposta era que tal currículo pudesse ser cumprido num período de quatro anos por pessoas de instrução secundária ou normal e em dois anos por pessoas de instrução superior. Cada ano letivo deveria ser dividido em dois semestres e composto pelas seguintes etapas:

1. Na primeira, far-se-á o estudo da Psicologia geral, baseado nas ciências biológicas e naturais, que serão estudadas no que interessam à Psicologia (biologia, anatomia e fisiologia, física e química). Nesse período, far-se-á também o estudo da propedêutica filosófica e de problemas particulares da lógica. 2. À segunda, corresponde o estudo da Psicologia diferencial e coletiva, baseado também nas ciências naturais, completado, entretanto, pelas ciências sociais e filosóficas (antropologia, sociologia, economia política, história da filosofia, teoria do conhecimento, teoria das ciências naturais, nas partes que apresentam interesse para a formação de psicologistas). 3. A última abrange os cursos de Psicologia aplicada e os cursos monográficos de especialidades 
psicológicas e ciências afins (Psicologia da criança, história da Psicologia, capítulos de ética e de estética, etc.) (Radecki, 1932, citado por Centofanti, 1982, p. 20).

Assim, com a criação do Instituto de Psicologia e lançadas as bases do currículo para formação dos profissionais, o curso superior em Psicologia seria iniciado no primeiro semestre de 1933 (Centofanti, 1982). Porém, após sete meses de criação do instituto, ele foi extinto em 24 de outubro de 1932, pelo decreto presidencial n. 21.999, "sendo seus respectivos serviços anexados, sem aumento de despesa, à Assistência a Psicopatas" (Decreto n. 21.999, 1932, s. p.).

Centofanti (1982) destaca que os prováveis motivos que teriam justificado o fechamento do instituto seriam: o intermédio de setores influentes da psiquiatria; a pressão de grupos católicos sobre o governo; a insuficiência financeira do Estado somada à quebra da expectativa de que o Instituto viesse a ser autofinanciável. Jacó-Vilela (2002) discorda da última justificativa e endossa o entendimento de que as duas primeiras sejam verossímeis, haja vista as divisões de poder/espaço que a profissionalização da Psicologia poderia ocasionar na Medicina e o potencial da Psicologia científica de subverter a hegemonia do discurso religioso católico no campo das ideias psicológicas.

A abertura e a extinção precoce do Instituto de Psicologia evidenciam um campo de tensões políticas e ideológicas que subjaz à formação em Psicologia desde seus primórdios no país. Como veremos, o diálogo-embate com sujeitosinstituições do conhecimento, como filósofos, médicos, educadores, religiosos, entre outros, segue imprimindo marca importante no movimento de reconhecimento e consolidação da Psicologia ao longo das décadas seguintes. Esse processo não pode, portanto, ser desconsiderado em nossa discussão sobre o conceito de formação subjacente às propostas curriculares para a Psicologia brasileira.

Nessa linha de análise, encontramos no currículo de formação em Psicologia apresentado por Waclaw Radecki a defesa de um modo específico de fazer Psicologia, orientada principalmente pelo modelo positivista e experimental. Tal postura, tributária das influências recebidas pelo proponente, acompanha-o desde seus primeiros trabalhos, nos quais se perguntava: "em que critérios poderia se apoiar para tornar o psicológico independente do pensamento filosófico-religioso e fundamentá-lo na biologia" (Radecki, 1953, citado por Centofanti, 1982, p. 6).

Além disso, com o currículo proposto por Radecki, ao psicólogo seria ofertada uma formação centrada na aplicação da técnica, com vistas a subsidiar outras áreas, particularmente para o auxílio de tarefas da Medicina em suas investigações acerca das doenças mentais, em consonância com os objetivos 
primordiais do Laboratório de Psicologia Experimental (Mancebo, 1999). Não se vê nesta proposta elementos do modelo multifatorial que caracterizaria uma formação generalista. A primazia dos aspectos biológicos oblitera a consideração de outras dimensões como as relações comunitárias, familiares, laborais, econômicas e culturais, delineando um conceito de formação especialista como sustentáculo deste projeto curricular.

Analisando a atuação de Radecki, Centofanti (1982) defende que ele pretendia que $\mathrm{o}$ instituto fosse tanto um núcleo científico com orientação acadêmica quanto um centro de formação de técnicos. E, para que o psicólogo brasileiro estivesse afeito a um lugar de "auxiliar" das práticas médicas e das necessidades sociais e práticas, entendia que a investigação experimental do fenômeno psíquico deveria orientar a introdução dos conhecimentos teóricos, metodológicos, éticos e filosóficos inerentes à prática profissional.

Com Jacó-Vilela (2002), compreendemos que a ideia de formação almejada por ele se caracterizava por uma perspectiva epistemológica e metodológica centrada no positivismo e no experimentalismo, em consonância com movimentos internacionais que defendiam tal perspectiva como a única possível para a edificação da Psicologia. Ainda segundo a autora, a proposta curricular de Radecki é próxima do currículo profissional da Psicologia aprovado em 1962, porém, dadas as já referidas circunstâncias do contexto cultural e social da época, não foi possível implementar, já na década de 1930, o primeiro currículo de formação profissional do psicólogo, o que postergou em 30 anos o reconhecimento legal da profissão pelo Estado brasileiro. Embora adiado, o processo de autonomização da Psicologia dava sinais de que já não poderia mais ser contido, sobretudo com a intensificação do processo de industrialização pelo qual passava o Brasil à época, fenômeno que demandava da educação "novas" intervenções na (trans)formação dos educandos.

A despeito da ausência de regulamentação, as Escolas Normais, os Laboratórios de Psicologia e as Faculdades, acolhedores que foram do conhecimento psicológico, mantiveram e gradativamente intensificaram suas relações com a Psicologia. Esse processo culminou na publicação das Portarias no. 272 (1946) e no. 328 (1946) que - em resposta ao Decreto-Lei n. 9.092 do mesmo ano - regularam a autorização para que as faculdades de filosofia formassem especialistas em Psicologia no Brasil. Ao estabelecer especificidades e condições para que os interessados no diploma de especialista em Psicologia pudessem alcançá-lo, este decreto favoreceu significativamente 0 avanço da profissionalização da Psicologia no país.

Nas portarias é possível apreender as seguintes preocupações com a 
formação dos psicologistas (ou especialistas em Psicologia): preparo específico, teórico, experimental e prático de modo intimamente interdependente; consideração do método experimental como método da Psicologia, a fim de garantir sua "predominância científica"; utilização do método clínico, entendendoo também como uma arte, capaz de alcançar a personalidade com seus problemas afetivos e de ajustamento para além dos aspectos lógicos, onde ciência e arte poderiam vir a constituir uma "sabedoria" à disposição do psicólogo; a probabilidade como perspectiva do trabalho do psicólogo; e a predominância do espírito científico. De acordo com Cabral (1953), nesta perspectiva, "só quando teoria, espírito experimental e habilidade técnica se unem num todo solidário, é que podemos afirmar estar frente a um psicologista" (p. 43).

Dado que a regulamentação teve início na esfera da especialização, o que fica evidente é que a formação basilar dos profissionais que alcançaram os primeiros diplomas oficiais de psicólogos brasileiros (psicologistas/especialistas em Psicologia) era oriunda de outras áreas, especialmente Medicina, Pedagogia, Ciências Sociais e Filosofia, sendo o conhecimento próprio da Psicologia complementar às suas formações de origem. A multiplicação de instituições e profissionais ligados à Psicologia nesse período, sem haver o reconhecimento do Estado de uma formação específica para profissionais psicólogos, tornou-se um fenômeno complexo e a utilização técnica diversificada colocava em risco a própria credibilidade da profissão. Segundo o Conselho Federal de Psicologia (1988), esse fenômeno marcou sensivelmente o desenvolvimento da profissão no país inclusive as proposições curriculares seguintes - evidenciando uma polarização: de um lado, os especialistas em Psicologia graduados em Ciências Sociais e Filosofia estavam preocupados com os aspectos teóricos; por outro, os especialistas em Psicologia com graduação em Pedagogia se envolviam com os testes psicológicos.

Os profissionais bacharéis e licenciados em outras áreas, apropriando-se do conhecimento especializado da Psicologia, foram aos poucos sendo transformados em profissionais especialistas e pesquisadores da área, aptos, oficialmente, ao exercício da profissão no país. Muitos destes que alcançaram os primeiros diplomas de especialistas compuseram o corpo docente dos primeiros cursos de graduação em Psicologia que foram emergindo no país, mesmo sem possuírem a graduação nos moldes que hoje conhecemos.

\section{O reconhecimento do Estado: o currículo mínimo de 1962}

O crescimento dos cursos de especialização em Psicologia exacerbou a 
necessidade de padronização e regulamentação da formação do psicólogo, caracterizando um período de busca por institucionalização da formação. É diante desse contexto de expansão e da necessidade de estabelecer uma caracterização para o fazer desse "novo" profissional que, em 1953, o Conselho Nacional de Educação solicitou uma proposta para a formação dos psicólogos aos diferentes atores que se organizavam em torno da Psicologia (Seixas, 2014; Esch \& JacóVilela, 2012).

A resposta a essa solicitação gerou movimentos divergentes dentro do espaço psi, uma vez que a compreensão acerca de qual o melhor modelo para formar o profissional da Psicologia não se apresentou de maneira uníssona. Os muitos debates travados à época foram protagonizados particularmente pelos representantes do Instituto de Seleção e Orientação Profissional (ISOP), Associação Brasileira de Psicotécnica (ABP), Associação Brasileira de Psicólogos, Sociedade de Psicologia de São Paulo, Faculdades de Filosofias da Universidade do Brasil e da Universidade de São Paulo (Rudá, Coutinho, \& Almeida-Filho, 2015; Seixas, 2014).

Nesse campo de divergências e confluências surgem posicionamentos importantes do ISOP e da ABP, com propostas de formação numa perspectiva especialista-tecnicista que foram vetadas, pois a possibilidade de regulamentar a atividade clínica do psicólogo (diagnóstica e psicoterápica) feriu interesses da classe médica que identificou nesse campo a supremacia de suas atuações (Mota, Cara \& Miranda, 2018). Em 1958, através do Projeto de Lei n. 3.825-A/58 enviado ao Congresso Nacional após o parecer no 412 da Comissão de Ensino Superior do Ministério da Educação, ficou implícito que, na atuação clínica, o psicólogo seria no máximo um assistente técnico do médico, sugestão também vetada durante a tramitação no Congresso (Rudá e outros, 2015).

Em resposta, a Associação Brasileira de Psicólogos conjuntamente com a Sociedade de Psicologia de São Paulo encaminhou proposta substituindo o termo "exercícios da prática psicoterápica" por "solução de problemas de ajustamento", resolvendo por essa via o dilema da relação entre Medicina e Psicologia sem retirar a autonomia desta última para a prática clínica (Seixas, 2014). O projeto apresentado por esse coletivo consistia em seis anos de formação, divididos entre teoria e prática, competindo ao aspirante a psicólogo escolher, no período de finalização, uma das três áreas clássicas de atuação: clínica, escolar e industrial. O intuito era que a Psicologia caminhasse para um lugar autônomo e de relevância para o mercado por possuir um corpo de conhecimentos e técnicas que lhe caracterizaram como profissão independente das demais.

Em meio a todos esses debates, em 1953 teve início o primeiro curso de 
graduação em Psicologia no Brasil, promovido pela Pontifícia Universidade Católica do Rio de Janeiro (PUC/RJ), seguida em 1956 pela PUC-RS e em 1958 pela Universidade de São Paulo (USP). Gradativamente os cursos de Psicologia foram se expandindo para outras localidades, mesmo sem possuírem ainda o aval oficial do Estado (Esch \& Jacó-Vilela, 2012).

Finalizando sua tramitação no Congresso com poucas alterações à última proposta mencionada, em 27 de agosto de 1962, a regulamentação da profissão do psicólogo foi aprovada no Brasil por meio da Lei n. 4.119 de 1962. No parágrafo $1^{0}$ do seu $13^{\circ}$ artigo foram constituídas como funções privativas do psicólogo: "a) diagnóstico psicológico; b) orientação e seleção profissional; c) orientação psicopedagógica; d) solução de problemas de ajustamento", devendo este profissional utilizar os métodos e técnicas psicológicas a fim de realizar com êxito a execução dessas funções.

Enquanto a Lei n. 4.119 (1962) dispôs sobre os aspectos gerais e administrativos dos cursos de formação em Psicologia, foi o Parecer n. 403 (1962), emitido pelo Conselho Federal de Educação e aprovado em 19 de dezembro do mesmo ano, que permitiu a efetivação da resolução que instituiu o currículo mínimo e o tempo de duração para a formação profissional. Assim, foi definido que o curso de Psicologia, em nível de bacharelado e licenciatura, teria duração de quatro anos contendo no mínimo as seguintes disciplinas: fisiologia; estatística; Psicologia geral e experimental; Psicologia do desenvolvimento; Psicologia da personalidade; Psicologia social; psicopatologia geral.

Para obtenção do título de psicólogo, deveria ser acrescido às disciplinas supracitadas o curso das matérias: técnicas de exame profissional e aconselhamento psicológico e ética profissional. Por fim, ao estudante, foi facultado escolher três dentre as seguintes disciplinas: Psicologia do excepcional; dinâmica de grupo e relações humanas; pedagogia terapêutica; Psicologia escolar e problemas de aprendizagem; teorias e técnicas psicoterápicas; seleção e orientação profissional; Psicologia da indústria. Para diplomação no curso era ainda obrigatório o treinamento da prática profissional sobre supervisão em campo de estágio, no caso da titulação de psicólogo (Parecer n. 403, 1962).

Segundo Jacó-Vilela (2002), na proposta de formação vigente no currículo mínimo, o "caráter científico" estava fundamentado no positivismo, feito que levou a formação a ser diferenciada entre formação básica (bacharelado teórico) e aplicada (formação técnica do psicólogo). Coimbra (1999) ressalta que os principais pressupostos contidos na proposta são: objetividade, tecnicismo, neutralidade e cientificidade. A ênfase no paradigma científico ancorado no positivismo lógico inibiu, naquele momento, a possibilidade de abertura para 
outras perspectivas teórico-epistemológicas que poderiam ser aproveitadas no campo, como a Fenomenologia e a Psicanálise (Fernandes, Seixas \& Yamamoto, 2018).

É possível, pois, compreender que todos esses fatores confluíram para caracterizar a formação presente no currículo mínimo de 1962 como uma formação especialista, com fins de aplicação da técnica e distante das problematizações contextuais que incidem sobre o ser humano, características que, de modo amplo, revelam o cenário ideológico, político e cultural da época. Nesse sentido, é interessante notar que, ainda que o artigo primeiro da Lei n. 4.119 (1962) considere que os cursos de Psicologia devam acontecer nas faculdades de Filosofia, é no Parecer n. 403 (1962) que se faz evidente a expectativa por um modo específico de filosofar:

É imperativo que se acentue o caráter científico dos estudos a serem realizados, que só assim há de ser possível assegurar à Psicologia a posição de relêvo que lhe cabe no concerto das chamadas profissões liberais e, pari passu, evitar as improvisões que, do charlatanismo a levariam, fatalmente ao descrédito. Estas considerações dão a medida dos cuidados que devem presidir a elaboração do respectivo currículo mínimo (Parecer n. 403, 1962, s. p.).

A prevalência de um modo específico de pensar em Psicologia, marcado pela orientação positivista, então entendido como único científico, é um fato marcante no momento de sua constituição enquanto profissão, corroborado pela própria disposição dos conteúdos presentes no currículo mínimo que vislumbraram a caracterização do perfil do egresso. Um traço marcante desse currículo é a busca pela aplicação das teorias psicológicas, ou seja, a Psicologia aplicada nas diferentes áreas, culminando em modelos de atuação privatista, individual e, de modo amplo, desconectado da realidade brasileira (Ferreira Neto, 2010). Para Seixas (2014), a legitimação garantida pelo Estado, por meio do estabelecimento do currículo mínimo, tornou essa formação inicial do psicólogo basicamente positivista, tendo na técnica o ponto central, gerando, muitas vezes, a descontextualização dos sujeitos e de suas questões.

As consequências desse currículo mínimo têm sido debatidas ao longo dos anos (Coimbra, 1999; Esch \& Jacó-Vilela, 2012; Ferreira Neto, 2010; Rudá e outros, 2015; Seixas, 2014), prevalecendo o entendimento de que sua proposta de formação promoveu uma "cultura psi" que fomentou o esquecimento da dimensão social e a patologização do sujeito na esteira do empenho de resolução dos "problemas de ajustamento". Ferreira Neto (2010) aponta ainda outro fator transversal ao desenvolvimento inicial da Psicologia regulamentada - que teria 
contribuído para o fortalecimento dessa cultura psi: o milagre econômico brasileiro que, entre 1968 e 1973, colocou as classes sociais média e alta dentro dos padrões do capitalismo industrial. Como nas sociedades industriais os processos de subjetivação típicos tendem a se caracterizar por alta valorização da interioridade psicológica - em virtude da busca pela ascensão social por meio dos méritos pessoais -, a vida individual é considerada com maior ênfase. Com isso, a Psicologia, ancorada no currículo mínimo, conformada enquanto um serviço de difícil acesso aos que detinham baixo poder aquisitivo, encontrou na nova elite brasileira o seu nicho de mercado, consolidando no imaginário social a figura do psicólogo como inerente à condição de clínico.

É válido destacar que as primeiras proposições curriculares do curso de Psicologia previam como campos cruciais de atuação a clínica, a escola e a indústria. Porém, a formação recebida pela primeira geração de psicólogos no país, somada ao contexto sócio-político da época, aguçou um modo específico de fazer Psicologia e culminou, de modo amplo, na construção do perfil do egresso do curso como um profissional liberal, com práticas individuais e autônomas, o que contribuiu para a construção de um imaginário social que vincula este profissional à clínica (Ferreira Neto, 2010; Rudá e outros, 2015; Seixas, 2014).

O crescente aumento do número de psicólogos no país e as consequentes mudanças na conjuntura socioeconômica foram aos poucos colocando em xeque essa concepção de formação, fazendo com que surgissem questionamentos e reformulações nas diretrizes curriculares, sobretudo a partir da década de 80 . Não adentraremos em tais reformulações (pós 1962) aqui, mas destaca-se sua importância para a complexificação do conceito de formação em Psicologia no Brasil.

\section{Discussão}

A partir dos dados apresentados torna-se possível verificar que a Psicologia no Brasil se fez presente de modo antecipado à regulamentação da profissão. $O$ conhecimento psicológico que subsidiou a construção do currículo mínimo da profissão é oriundo de uma aplicação de teorias e técnicas que na maioria das vezes foi importado de outros países e aplicados em campos de conhecimentos já existentes e consolidados no país, como a Medicina, a Pedagogia, as Ciências Sociais e a Filosofia.

Conforme apontado por Ferreira Neto (2010), Coimbra (1999) e Mancebo (1999), dado os novos padrões de subjetivação oriundos do desenvolvimento industrial emergente no Brasil a partir da década de 1950, onde o elemento 
"psíquico", "intraindividual" e de "autodesenvolvimento" ganharam força, tornouse cada vez mais presente a necessidade de regulamentar um currículo mínimo e exclusivo para a formação do psicólogo no Brasil. Além disso, houve uma influência inclusive por uma certa leitura da Psicanálise que emergia como um campo capaz favorecer as "subjetividades forjadas" no novo cenário industrial (Coimbra, 1999). Neste contexto, somado a uma crescente expansão do ensino superior, sobretudo em instituições particulares, em 1962, a Psicologia teve o seu currículo mínimo regulamentado pelo Estado brasileiro.

Esta proposta foi aprovada em consonância com a tradição que vinha sendo pensada para a profissão no país, a partir de teorias psicológicas hegemônicas e apresentou uma tendência a um modo específico de pensar e fazer em Psicologia, afinado ao positivismo, o que culminou numa formação especialista com uma busca significativa pela continuidade de aplicação de teorias psicológicas e, por consequência, no distanciamento das questões contextuais. Nesse sentido, em consonância com o pensamento de Esch e Jacó-Vilela (2012), consideramos que a proposição curricular de 1962 não diferiu em grande medida da proposta pensada por Waclaw Radecki em 1932. Portanto, sem grandes mudanças de perspectivas nos currículos propostos em 1932 e em 1962, a Psicologia brasileira apenas retardou, em 30 anos, a aprovação do seu currículo inicial.

Para o Conselho Federal de Psicologia (2018), há na Psicologia, desde sua origem, uma caracterização híbrida e plural. Esta se efetivaria através de uma "formação generalista" que se traduziria por contemplar "o caráter multifacetado da ciência psicológica" e apontaria para uma "diversidade de possibilidades tanto no que se refere às suas bases epistemológicas e metodológicas, quanto às suas áreas de atuação" (p. 38). Carvalho e Sampaio (1997) apontam que o "espírito" da lei que regulamentou Psicologia no Brasil ( $N^{\circ} 4119 / 62$ ), voltou-se para uma formação generalista, pois pretendia habilitar o profissional psicólogo a atuar em qualquer área da Psicologia. Já o parecer n. 403 de 1962, que estabeleceu o currículo mínimo, evidencia a intenção de "manter a média do pensamento dominante" (s.p.) já existente nos centros de Psicologia aplicada do país, como sendo uma primeira aproximação do currículo desejado. Este mesmo parecer deixa clara a necessidade de que a formação profissional atenda às demandas próprias do psicólogo na "escola, na empresa, na clínica e onde quer que a sua presença seja reclamada" (Parecer n. 403, 1962, s. p.).

O fato de que a formação inicial aprovada em 27 de agosto 1962 através da lei n 4119, tenha tido um "espírito" generalista, assim como características híbridas e plurais, é suficiente para garantir que esta tenha sido, de fato, uma formação generalista? Dado o contexto interposto à Psicologia no período de sua 
gênese regulamentada, apontamos que em termos práticos a formação generalista não foi uma realidade na formação da primeira geração de profissionais psicólogos do Brasil. $O$ fato de haver uma formação polivalente que visava mais de um campo de atuação para o psicólogo (clínica, escolar e industrial), não nos permite afirmar que esta tenha sido de fato generalista, uma vez que a formação generalista se caracteriza por garantir ao graduado "a articulação de distintos temas oriundos das áreas clássicas, independentemente do local de atuação ou do referencial teórico utilizado pelo profissional, mas sempre sensível ao seu contexto" (Bernardes, 2006, p. 29).

$\mathrm{Na}$ formação generalista espera-se que os profissionais formados sejam capazes de considerar em suas práticas ações voltadas à integralidade do sujeito que demanda intervenções da Psicologia, nas diversas áreas de atuação desse profissional. Segundo Chehuen Neto e outros (2014), espera-se ainda que os generalistas sejam capazes de fazer a utilização racional das tecnologias disponíveis, considerando a relação custo-benefício, além de desenvolver a capacidade de liderança e interdisciplinaridade. Para Bernardes (2006), a realidade da Psicologia não tem sido assim. O autor, ao considerar o tema da integralidade em suas investigações e relacioná-lo a proposta de formação "generalista" presente nas proposições curriculares da Psicologia, afirma que o conceito de formação generalista está banalizado e que a formação do psicólogo "jamais foi generalista". Em seu texto, o autor busca evidenciar que uma formação em Psicologia coerente com a proposta da integralidade, ainda demandará um intenso trabalho e argumenta que, na contramão de uma formação generalista, desde os seus primórdios, o que ocorreu na Psicologia foi uma "formação fragmentada, reducionista, liberal, individualizante e com especialização precoce" (Bernardes, 2006, p. 22).

Nessa perspectiva, ainda de acordo com Bernardes (2006), a formação generalista contribui para o rompimento com uma formação fragmentada - como é o caso da Psicologia - pois, ao buscar uma articulação entre distintos temas ou questões que derivam de um campo ou uma área de conhecimento, torna-se possível aproximar com maior clareza da complexidade que envolve as questões do campo psicológico. Desse modo, enquanto a formação especialista visa à aplicação de teorias em determinadas situações específicas, a formação generalista vislumbra relacionar o aparecimento do fenômeno à sua realidade contextual. Nesse sentido, é possível considerar que a formação especialista tenha sido uma marca importante da formação inicial em Psicologia no Brasil e suas influências remontam às contribuições do psicólogo polonês Waclaw Radecki, cujo interesse em tornar a linha de investigação experimental do fenômeno psicológico, 
bem como o psicológico enquanto instância independente do pensamento filosófico-religioso a fim de fundamentá-lo na biologia, figuraram como marcas importantes de suas contribuições para a Psicologia brasileira.

Ainda assim, é válido destacar que o modo de constituição da Psicologia brasileira se deu a múltiplas mãos, ou seja, diferentes atores e instituições estiveram envolvidos no processo de formulação do currículo mínimo. Isso nos exige considerar que, concomitante à regulamentação da profissão no país, já se fazia presente uma inquietação acerca do perfil profissional a ser alcançado pelo currículo aprovado, sendo uma provocação constante, desde os primórdios da profissão, a necessidade de uma formação no molde generalista.

Diante disso, é possível compreender que o anseio da formação generalista está perpassado pela busca da construção de um perfil profissional crítico e, por consequência, atento à complexidade da realidade, sendo este um "espírito" motivador para as construções curriculares da Psicologia. A perspectiva da formação generalista se opõe ao modelo de formação especialista, cuja perspectiva está centrada na compartimentalização de saberes e aplicação de técnicas, porém, foi a "lógica" especialista imposta pelo mercado de trabalho - que reivindicava intervenções especializadas e para isso oferecia melhores remunerações aos psicólogos - que marcou a inauguração da Psicologia no Brasil. Diante disso, a Psicologia nascente, disposta em três frentes prioritárias de atuação ou "onde quer que a sua presença seja reclamada" (parecer n. 403, s.p.), sem objeto de intervenção esclarecido e interessada na solução de "problemas de ajustamento", foi imediatamente absorvida pelo mercado que demandava intervenção nas recém criadas elites do milagre econômico que experimentavam o padrão de subjetivação próprio das sociedades industriais. Este marco serviu para promover a imagem do psicólogo ligado à figura do clínico e relacionar o lugar do especialista como sendo aquele que alcança melhor prestígio profissional, maior valorização econômica e melhor capacidade técnica de resolução clínica.

Para Pereira e Pereira Neto (2003), nas primeiras décadas da regulamentação da Psicologia no Brasil, deitar no divã era sinal de status social e este comportamento passou a ser incorporado por muitas pessoas das classes média e alta. Estes mesmos autores, valendo-se das contribuições de Langenbach (1988), consideram que a predominância da prática clínica na atuação do psicólogo brasileiro se dá também em virtude do seu caráter pouco ameaçador às forças ditatoriais vigentes à época, haja vista que a ênfase nos problemas de ajustamento íntimos e individuais ocultava problematizações das questões sociais. Assim, ainda que o desejo de uma formação generalista atravessasse a busca pela constituição da profissão do psicólogo brasileiro, esta não foi a característica norteadora e 
possível que vigorou a partir do currículo mínimo de 1962.

\section{Considerações finais}

As visões de ser humano e de mundo que dão sustentação às proposições formativas de cada campo profissional são cruciais para definições de lugares, papéis e compromissos daqueles que participam do processo formativo (Conselho Federal de Psicologia, 1988, 2018; Stein, 1930/2003). Essa afirmativa pode ser evidenciada a partir da análise e reflexão das propostas pioneiras da formação em Psicologia no Brasil que nos mostram distintos posicionamentos sociopolíticos e epistemológicos que culminaram, à época, na construção de um determinado perfil profissional do psicólogo no país, ancorado basicamente numa formação especialista, técnica e pautada nos parâmetros positivistas. Tudo isso nos revela que a visão de mundo e de ser humano prevalente à época - onde o sujeito e o mundo seriam passíveis de conhecimento através do método positivista entrelaçava e determinava as possibilidades de construções da formação para a Psicologia brasileira.

Essa análise nos revela a relevância de revisitar a gênese constitutiva do currículo da Psicologia, sobretudo para compreender aspectos de sua identidade enquanto ciência e profissão no país. O cenário polissêmico em que se dá a constituição da Psicologia brasileira é uma realidade importante e ainda pouco considerada na formação identitária dessa classe profissional. As divergências e convergências presentes nas diferentes propostas que visaram alcançar o perfil do graduado em Psicologia na década de 1960 e a consequentemente aprovação do currículo mínimo revelam muito mais uma reação às questões político-sociais e culturais da época do que a construção de um sentido próprio para a formação do psicólogo brasileiro. Este apontamento pode ser verificado nas necessárias revisões curriculares que se apresentaram imediatamente após a aprovação do currículo mínimo e que só foram formalmente alteradas com as diretrizes curriculares de 2004.

Em suma, nossa análise evidenciou que a discussão acerca da formação em Psicologia no Brasil foi perpassada num primeiro momento, em 1932, pelo adjetivo especialista que visou uma formação experimental, científica em conformidade com o modelo positivista, alinhada com os saberes da Medicina e interessada na aplicação de teorias. Já em 1962, onde finalmente o currículo mínimo foi aprovado após intensos embates entre diferentes atores e instituições, buscou-se uma formação mais ampliada e polivalente, sem alcançar, no entanto, o status de uma formação generalista. 


\section{Referências}

Antunes, M. A. M. (1997). Sobre a formação de psicólogos: aspectos históricos. Psicologia da Educação, 5, 35-56. Recuperado em 05 de julho, 2021, de https://revistas.pucsp.br/index.php/psicoeduca/article/view/42899/28563.

Autuori, M. (2014). Uma história do Instituto de Psicologia da Universidade Federal do Rio de Janeiro. Boletim - Academia Paulista de Psicologia, 34(86), 7-23. Recuperado em 05 de julho, 2021, de http://pepsic.bvsalud.org/pdf/bapp/v34n86/a02.pdf.

Bernardes, J. S (2006). Formação generalista em Psicologia e Sistema Único de Saúde. Em Conselho Federal de Psicologia. (Org.). I Fórum Nacional de Psicologia e Saúde Pública ( $p p$. 17-40). Brasília: Conselho Federal de Psicologia.

Cabral, A. (1953). Requisitos básicos da formação de psicologistas. Ciência e Cultura, 5(1), 43-44.

Carvalho, M. T. M. \& Sampaio, J. R. (1997). A formação do psicólogo e as áreas emergentes. Psicologia: ciência e profissão, 17(1), 14-19. Recuperado em 18 de julho de 2020, de http://pepsic.bvsalud.org/scielo.php?script=sci arttext\&pid=S141498931997000100003\&lng=pt\&tlng=pt.

Centofanti, R. (1982). Radecki e a Psicologia no Brasil. Psicologia: Ciência e Profissão, 3(1), 2-50. Recuperado em 05 de julho, 2021, de dx.doi.org/10.1590/S1414-98931982000100001.

Chehuen Neto, J. A., Sirimarco, M. T., Cândido, T. C., Ulhoa, C. M., Reis, B. P., \& Lima, V. M. (2014). Formação médica generalista: percepção do profissional e do estudante. HU Revista, 40(1 e 2). Recuperado em 05 de julho, 2021, de https://periodicos.ufjf.br/index.php/hurevista/article/view/2095.

Coimbra, C. M. B. (1999). Práticas "psi" no Brasil do "milagre": algumas de suas produções. Em A. M. Jacó-Vilela, F. Jabur \& H. B. Rodrigues (Org.s). ClioPsyché: histórias da Psicologia no Brasil (pp. 75-95). Rio de Janeiro: ClioPsyché. 
Conselho Federal de Psicologia (Org.). (1988). Quem é o psicólogo brasileiro? São Paulo: Edicon.

Conselho Federal de Psicologia (Org.). (2018). Ano da formação em Psicologia: revisão das diretrizes curriculares nacionais para os cursos de graduação em Psicologia. São Paulo: Conselho Federal de Psicologia.

Decreto n. 21.173 (1932, 19 de março). Converte o atual Laboratório de Psicologia da Colônia de Psicopatas, no Engenho de Dentro, em Instituto de Psicologia. Rio de Janeiro: Presidência da República.

Decreto n. 21.999 (1932, 24 de outubro). Extingue o Instituto de Psicologia, anexando os respectivos serviços, sem aumento de despesa, à Assistência a Psicopatas. Rio de Janeiro: Presidência da República.

Esch, C. F., \& Jacó-Vilela, A. M. (2012). A regulamentação da profissão e os currículos de formação psi. Em A. M. Jacó-Vilela, A. C. Cerezzo \& H. B. C, Rodrigues (Org.s). Clio-psyché: fazeres e dizeres psi na história do Brasil (pp. 17-24). Rio de Janeiro: Centro Edelstein de Pesquisas Sociais.

Fernandes, S., Seixas, P. \& Yamamoto, O. (2018). Psicologia e concepções de formação generalista. Psicologia da Educação, 47, 57-66. Recuperado em 05 de julho, 2021, de doi.org/10.5935/2175-3520.20180018.

Ferreira Neto, J. L. (2010). Uma genealogia da formação do psicólogo brasileiro. Memorandum, 18, 130-142. Recuperado em 05 de julho, 2021, de https://periodicos.ufmg.br/index.php/memorandum/article/view/6645/421 9

Jacó-Vilela, A. M. (2002). Idas e vindas do curso de Psicologia no Brasil. Revista do Departamento de Psicologia da UFF, 1(14), 11-22.

Langenbach, M. \& Negreiros, T. C. G. M. (1988). A formação complementar: um labirinto profissional. Em Conselho Federal de Psicologia (Org.). Quem é o psicólogo brasileiro? (pp. 86-99) São Paulo: Edicon.

Lei n. 4119 (1962, 27 de agosto). Dispõe sobre a formação em Psicologia e regulamenta a profissão de psicólogo. Brasília: Presidência da República. 
Mancebo, D (1999). Formação em psicologia: gênese e primeiros desenvolvimentos. Em A. M. Jacó-Vilela \& H. B. C. Rodrigues. (Orgs.). ClioPsyché: histórias da psicologia no Brasil. (pp. 93-120). Rio de Janeiro: UERJ/NAPE.

Massimi, M. (1990). História da Psicologia brasileira: da época colonial até 1934. São Paulo: E.P.U.

Massimi, M. (2016). História dos saberes psicológicos. São Paulo: Paulus.

Massimi, M., Campos, R. H. F. \& Brožek, J. (1996). Historiografia da Psicologia: métodos. Em R. H. F. Campos (Org.). Historiografia da Psicologia: pesquisa, formação, ensino (pp. 21-48). São Paulo: Educ; Anpepp.

Mota, A. M. G. F., Cara, B. S. \& Miranda, R. L. (2018). História da Psicologia, por quê? Estudos e Pesquisas em Psicologia, 18(4), 1049-1067. Recuperado em 05 de julho, 2021, de https://www.epublicacoes.uerj.br/index.php/revispsi/article/view/42222/29269.

Parecer n. 403. (1962, 19 de dezembro). Parecer do Conselho Federal de Educação sobre currículo mínimo dos cursos de Psicologia. Brasília: Ministério da Educação e Cultura. Recuperado em 25 de maio, 2020, de abepsi.org.br/wpcontent/uploads/2011/07/1962-parecern403de19621.pdf.

Parecer $n^{\circ}$ 412. (1957, 20 de setembro). Parecer da Comissão de Ensino Superior sobre a regulamentação da profissão de psicólogo. Rio de Janeiro: Ministério da Educação e Cultura. Recuperado em 05 de julho, 2021, de http://abepsi.org.br/wp-content/uploads/2011/07/1957-parecer412.pdf.

Penna, A. G. (1992). História da Psicologia no Rio de Janeiro. Rio de Janeiro: Imago.

Pereira, F. M. \& Pereira Neto, A. (2003). O psicólogo no Brasil: notas sobre seu processo de profissionalização. Psicologia em Estudo, 8(2), 19-27. Recuperado em 05 de julho, 2021, de https://dx.doi.org/10.1590/S141373722003000200003.

Piñeda, M. A. \& Jacó-Vilela, A. M. (2014). Ciencia psicológica y profesionalización 
en Argentina y Brasil: 1930-1980. Universitas Psychologica, 13(5), 20152033. Recuperado em 05 de julho, 2021, de https://psycnet.apa.org/doi/10.11144/Javeriana.upsy13-5.cppa.

Portaria n. 272 (1946, 13 de abril). Aprova as instruções reguladoras da execução do disposto nos artigos $5^{\circ}$ e $6^{\circ}$ do Decreto-lei no 9.092, de 26 de março de 1946. Rio de Janeiro: Ministério de Educação e Saúde.

Portaria n. 328 (1946, 13 de maio). Modifica e amplia instruções expedidas pela Portaria no 272, de 13 de abril do corrente ano. Rio de Janeiro: Ministério de Educação e Saúde.

Projeto de Lei no 3825, de 11 de abril de 1958 (1958, 11 de abril). Dispõe sobre os cursos de formação em psicologia e regulamenta a profissão de psicologista [transformado na Lei Ordinária 4119/1962]. Brasília: Câmara dos Deputados. Recuperado em 05 de julho, 2021, de: https://www.camara.leg.br/proposicoesWeb/fichadetramitacao?idProposica $0=216279$.

Rudá, C., Coutinho, D. \& Almeida-Filho, N. (2015). Formação em Psicologia no Brasil: o período do currículo mínimo (1962-2004). Memorandum, 29, 5985. Recuperado em 23 de agosto, 2019, de periodicos.ufmg.br/index.php/memorandum/article/view/6471.

Saviani, D. (2013). História das ideias pedagógicas no Brasil. - 4. Ed. - Campinas, SP: Autores Associados. - (coleção memória da educação).

Seixas, P. S. (2014). A formação graduada em Psicologia no Brasil: reflexão sobre os principais dilemas em um contexto pós-DCN. Tese de Doutorado, Programa de Pós-Graduação em Psicologia, Sociedade e Qualidade de Vida, Universidade Federal do Rio Grande do Norte, Natal, RN.

Stein, E (2003). Sobre el concepto de formación. Em E. Stein. Obras completas. V. IV: escritos antropológicos y pedagógicos. (pp. 127-148). (F. J. Sancho e col., Trads.) Vitoria, Espanha: El Carmen. (Publicação original de 1930). 


\section{Notas sobre os autores:}

Danillo Lisboa é psicólogo, doutorando em Psicologia pela Faculdade de Filosofia, Ciências e Letras de Ribeirão Preto, Universidade de São Paulo. E-mail: danillolisboa@yahoo.com.br

Carmen Lúcia Cardoso é psicóloga, professora Associada do Departamento de Psicologia e orientadora junto ao Programa de Pós-Graduação em Psicologia da Faculdade de Filosofia, Ciências e Letras de Ribeirão Preto, Universidade de São Paulo. E-mail: carmen@ffclrp.usp.br

Roberta Vasconcelos Leite é psicóloga, doutora em Psicologia pela Universidade Federal de Minas Gerais e professora-adjunta da Faculdade de Medicina da Universidade Federal dos Vales do Jequitinhonha e Mucuri, MG. E-mail: roberta.leite@ufvjm.edu.br

Yuri Elias Gaspar é psicólogo, doutor em Psicologia pela Universidade Federal de Minas Gerais e professor-adjunto da Faculdade Interdisciplinar de Humanidades da Universidade Federal dos Vales do Jequitinhonha e Mucuri, MG. E-mail: yuri.gaspar@ufvjm.edu.br

Data de submissão: 26.01 .2021

Data de aceite: 28.06 .2021 